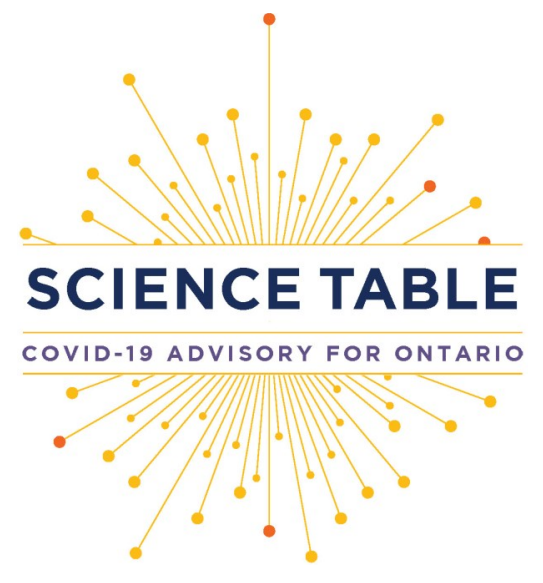

Version 1.0

Published: August 31, 2020

Citation: Jüni $P$, Maltsev $A$, Bobos $P$, et al. The Role of Children in SARS-CoV-2 Transmission. Science Briefs of the Ontario COVID-19 Science Advisory Table. 2020;1(3). https:// doi.org/10.47326/ocsat.2020.01.03.1.0

Author Affiliations: The affiliations of the members of the Ontario COVID-19 Science Advisory Table can be found at www.covid19 -sciencetable.ca.

Declarations of Interest: The declarations of interest of the members of the Ontario COVID-19 Science Advisory Table can be found at www.covid19-sciencetable.ca.

About Us: The Ontario COVID-19 Science Advisory Table is a group of scientific experts and health system leaders who evaluate and report on emerging evidence relevant to the COVID-19 pandemic, to inform Ontario's response. Our mandate is to provide weekly summaries of relevant scientific evidence for the COVID-19 Health Command Table of the Province of Ontario, integrating information from existing scientific tables, Ontario's universities and agencies, and the best global evidence. The Science Table summarizes its findings for the Health Command Table and the public in Science Briefs.

Correspondence to: Secretariat of the Ontario COVID-19 Science Advisory Table (info@covid19-sciencetable.ca)

Copyright: 2020 Ontario COVID-19 Science Advisory Table. This is an open access document distributed under the terms of the Creative Commons Attribution License, which permits unrestricted use, distribution, and reproduction in any medium, provided that the original work is properly cited.

\title{
The Role of Children in SARS-CoV-2
}

\section{Transmission}

Peter Jüni, Antonina Maltsev, Pavlos Bobos, Upton Allen, Yoojin Choi, James P. Connell, Gerald A. Evans, Douglas G. Manuel, Allison McGeer, Fahad Razak, Beate Sander, Brian Schwartz, Ashini Weerasinghe, Sarah E. Wilson on behalf of the Ontario COVID-19 Science Advisory Table

\section{Key Message}

Early suggestions that children are considerably less important for SARS-CoV-2 transmission than adults are not confirmed by recent research. Children could play a relevant role, and public health interventions could be as relevant and impactful to mitigate transmission in children as in adults.

\section{Summary}

\section{Background}

Children are underrepresented in COVID-19 case statistics and are less likely to become seriously ill or die.

Early studies suggested that the evidence to support school closure to contain the COVID-19 pandemic was weak and that SARS-CoV-2 transmission was low in Australian schools during the early stages of the pandemic.

This caused some to prematurely conclude that children are considerably less important drivers of SARS-CoV-2 transmission than adults.

However, recent reports suggested high viral loads in nasopharyngeal swabs of symptomatic young children, and high transmission among children and adolescents attending an overnight youth camp.

\section{Questions}

What is the role of children in SARS-CoV-2 transmission?

\section{Findings}

Contact tracing studies reported that children younger than 10 years of age are less likely to test positive for SARS-CoV-2. These studies can underestimate the infection rate in children if infected children are more likely to be asymptomatic than infected adults. In a retrospective analysis of outbreak investigations in Ontario, young children were three times more likely to be asymptomatic after SARS-CoV-2 infection than older individuals.

Seroprevalence studies found young children less likely to have antibodies against SARS-CoV-2. These studies were conducted when schools had been closed, therefore children were likely to have fewer social contacts than during regular school schedules.

A biological explanation for the potential lower susceptibility of younger children to SARS-CoV-2 infection could be a lower density of ACE2, the receptor used by SARS- 
CoV-2 to infect cells, in the nasal mucosa. However, if children have more social contacts or react differently to public health interventions than adults, this could offset the potential biological advantage offered by lower ACE2 density.

A retrospective cohort study of an outbreak in attendees of an overnight youth camp found younger children were at least as likely as older attendees to be infected with SARS-CoV-2. This suggests that young children can have attack rates similar to those of older children, adolescents and adults under conditions that are conducive to outbreaks, such as high local transmission and overnight stays in dormitories.

SARS-CoV-2 RNA levels in swabs from children and adolescents with COVID-19 are similar to those in adults with COVID-19, and infectious SARS-CoV-2 was detected in children of all ages.

Ecological studies found that school closures were associated with a containment of the COVID-19 pandemic, but it was not possible to disentangle the independent impact of school closures from the impact of other public health interventions.

Case studies of school openings in different countries suggest that school openings can be safe provided that local transmission is low and appropriate measures are in place to prevent or contain potential outbreaks in schools.

\section{Interpretation}

Early suggestions that children are considerably less important drivers of SARS-CoV2 transmission than adults are not confirmed by more recent research.

Children could play a relevant role in SARS-CoV-2 transmission and school closures may have been important contributors to the containment of the COVID-19 pandemic.

Public health interventions could be as relevant and impactful to control transmission in children as in adults. It appears therefore important to include children as part of any surveillance, testing and control strategy, while bearing in mind that children are more likely than adults to remain asymptomatic after SARSCoV-2 infection.

\section{Children younger than 10 years* of age as compared with adults}

Are they less likely to get infected with SARS-CoV-2?

Uncertain

Once infected, are they less likely to shed the virus?

Uncertain

Are they less likely to infect others?

Uncertain

Are they less likely to become symptomatic? Yes

Are they less likely to become severely ill? Yes

\section{Children 10 years* of age or older as compared with adults}

Are they less likely to get infected with SARS-CoV-2? No

Once infected, are they less likely to shed the virus? No

Are they less likely to infect others? No

Are they less likely to become symptomatic? Yes

Are they less likely to become severely ill? Yes

${ }^{*}$ Age cut-off of 10 years is approximate, as cut-offs vary between studies. 


\section{Background}

In respiratory infectious diseases other than COVID-19, children and adolescents have been considered key drivers of transmission. In an analysis of surveillance data and school holiday schedules in France between 1985 and 2006, Cauchemez et al. estimated that seasonal school holidays prevented $16-18 \%$ of seasonal influenza cases. ${ }^{1} \mathrm{Wu}$ et al. estimated that influenza transmission was reduced by $25 \%$ during the 2009 influenza pandemic in Hong Kong when secondary schools closed. ${ }^{2}$

Children are underrepresented in COVID-19 case statistics ${ }^{3}$ and are less likely to become seriously ill or die..$^{4-6}$ In a retrospective cohort study of 13,323 COVID-19 cases reported in Italy between February 20 and March 15, 2020, Livingston and Bucher reported that children aged 0 to 18 years accounted for $1.2 \%$ of cases and that no deaths were recorded. ${ }^{3}$

In another retrospective cohort study of 171 children with SARS-CoV-2 infection admitted to Wuhan Children's Hospital in China between January 28 and February 26,2020 , Lu et al. found that most children had mild disease or were asymptomatic. Three children required intensive care and invasive mechanical ventilation, and one child died; all had pre-existing medical conditions. ${ }^{4}$

Of 36,950 cases reported in Ontario between January 15 to July 13, 2020, only 979 cases were reported in children aged 0 to 14 years (2.6\%). Out of 4,525 hospital admissions for COVID-19 in Ontario during the same period, only 15 occurred in children of this age group (0.3\%), with only 2 ICU admissions, and no deaths. ${ }^{7}$

A rapid review by Viner et al. ${ }^{8}$ published on April 6, 2020 concluded that "the evidence to support national closure of schools to combat COVID-19 is very weak and data from influenza outbreaks suggest that school closures could have relatively small effects on a virus with COVID-19's high transmissibility and apparent low clinical effect on school children." The article was highly influential. By August 15, it was picked up by 223 news outlets, tweeted by 4,278 users, and cited by 246 articles according to Google Scholar. It has been interpreted as evidence of a lack of effectiveness of school closures, when in fact evidence was lacking at the time.

A non-peer-reviewed report from New South Wales, Australia, which was made publicly available on April 26, 2020, indicated that only two COVID-19 cases were found between March 5 and April 3, 2020 among 863 close contacts of 18 COVID-19 cases in 15 primary and secondary schools. ${ }^{9}$ The study was conducted when the incidence in New South Wales fluctuated at relatively low levels, from 5 daily cases per 10 million on March 5, to a peak of 267 daily cases per 10 million on March 27, and back to 133 daily cases per 10 million on April 3. From March 22 onwards, children were encouraged to stay home for distance learning even though schools remained open, for when home schooling was not an option. Only about two thirds of close contacts received PCR or serological testing, and asymptomatic contacts were considerably less likely to be tested than symptomatic contacts. ${ }^{9,10}$ This caused some to prematurely conclude that children are considerably less important drivers of SARS-CoV-2 transmission than adults. ${ }^{11}$

However, recent reports have suggested high viral loads in nasopharyngeal swabs of symptomatic young children, ${ }^{12}$ and a high degree of transmission among children and adolescents attending an overnight youth camp. ${ }^{13}$

\section{Questions}

What is the role of children in SARS-CoV-2 transmission? 


\section{Findings}

\section{Contact Tracing Studies}

Zhang et al. conducted a retrospective cohort study of PCR testing of all contacts of known COVID-19 cases in Hunan, China, from January 16 to March 1, 2020, and found that the 756 contacts aged 0 to 14 years were less likely to test positive for SARS-CoV-2, compared to the 5733 contacts aged 15 to 64 years (odds ratio 0.34, $95 \%$ confidence interval 0.24 to 0.49$){ }^{14}$

In a retrospective cohort study of 10,592 household contacts of 5,706 cases infected with SARS-CoV-2, who underwent PCR testing as part of the South Korean COVID-19 contact tracing program, Park et al. found the 57 household contacts of children under 10 years of age approximately half as likely to test positive than contacts of adults, but the number of contacts for this youngest age group was small. ${ }^{15}$ Conversely, the 231 household contacts of children and young adults aged 10 to 19 years tended to be more likely to test positive than household contacts of adults. ${ }^{15}$

Both contact tracing studies ${ }^{14,15}$ could have underestimated the infection rate in children if infected children are more likely to be asymptomatic than infected adults, even if all household contacts were tested. For example, an asymptomatic child could unknowingly have infected the first symptomatic COVID-19 case of a family. By the time of contact tracing, the asymptomatic child who transmitted the virus could have a negative PCR test, ${ }^{16}$ and therefore go undetected.

Young children appear indeed more likely to be asymptomatic after SARS-CoV-2 infection than adults. In a non-peer-reviewed retrospective analysis of anonymized data from 4,384 individuals included in COVID-19 outbreak investigations in Ontario who tested positive for SARS-CoV- $2,{ }^{17}$ children under 10 years of age were three times more likely to be asymptomatic than older individuals (odds ratio 3.03, 95\% confidence interval 1.39 to 6.59 ; Fisman DN, personal communication).

\section{Seroprevalence Studies}

In a population-based seroprevalence study conducted between April 6 and May 9, 2020, in 2,766 participants in Geneva, Switzerland, Stringhini et al. found that only one out of 123 children aged 5 to 9 years had antibodies against SARS-CoV-2 (0.8\%), whereas children and young adults aged 10 to 19 years were as likely as adults aged 20 to 49 years to have antibodies. They estimated that children aged 5 to 9 years were only $30 \%$ as likely to have antibodies against SARS-CoV- 2 than middle-aged adults (risk ratio $0.32,95 \%$ confidence interval 0.11 to 0.63 ). ${ }^{18}$

In a nationwide population-based seroprevalence study conducted between April 27 and May 11, 2020, in 61,075 randomly selected participants in Spain, Pollán et al. found that $3.1 \%$ of 2,846 children aged 5 to 9 years ( $95 \%$ confidence interval 2.2 to $4.2 \%$ ) and $4.0 \%$ of 3,428 children aged 10 to 14 years ( $95 \%$ confidence interval 3.1 to $5.0 \%)$ had antibodies against SARS-CoV-2, as compared with approximately $6 \%$ among adults aged 45 years or older. ${ }^{19}$

Both seroprevalence studies ${ }^{18,19}$ were conducted during nationwide school closures when children were prevented from engaging in normal activities, which limited opportunities for SARS-CoV-2 transmission.

\section{Biological and Behavioural Factors}

A biological explanation for the potential lower susceptibility of younger children to SARS-CoV-2 infection could be a lower density of ACE2, the receptor used by SARSCoV-2 to infect cells, in the nasal mucosa. When analyzing samples from 305 
participants, Bunyavanich et al. found a lower density of ACE2 in 45 children aged less than 10 years than in older participants. ${ }^{20}$ Yonker et al. recently confirmed these findings. ${ }^{21}$

Children have a high number of social contacts relative to adults, and may react differently to public health interventions. ${ }^{22,23}$ In a study of contact patterns of 7,290 children and adults from eight European countries, Mossong et al. found, for example, that children aged 10 to 14 years had the highest number of daily contacts among all age groups. ${ }^{23}$ A potential lower biological susceptibility of children and adolescents to SARS-CoV-2 infection could therefore be offset by behavioural factors.

Children may have social and developmental challenges with some public health measures, such as physical distancing, masks, and cohorting. ${ }^{24}$ Public health measures will therefore need to be tailored to the age-specific social and developmental requirements of children, while also considering their potential challenges and harms.

\section{Viral RNA Levels}

In a cross-sectional single-centre study in 145 consecutive patients, with mild to moderate symptomatic COVID-19, Heald-Sargent et al. found that children younger than 5 years of age had higher SARS-CoV-2 RNA levels in their nasopharyngeal swabs than children aged 5 to 17 years and adults. ${ }^{12} \mathrm{~A}$ limitation of the study was that asymptomatic children infected with SARS-CoV-2 were not included.

In a cross-sectional study available as a non-peer-reviewed preprint, Jones et al. analyzed SARS-CoV-2 RNA levels from nasopharyngeal swabs of 3,712 patients with confirmed SARS-CoV-2 infection, including 15 children below 10 years of age, and 33 children and adolescents aged 10 to 19 years, and found similar SARS-CoV-2 levels across all age groups. ${ }^{25}$ Similar results were reported by Yonker et al., who found that nasopharyngeal SARS-CoV-2 RNA levels among 49 individuals aged 0 to 22 years were similar in younger and older individuals. ${ }^{21}$

In a retrospective cohort study conducted between February 18 to March 31, 2020, in 91 consecutive children and adolescents with a median age of 11 years (range 0 to 18 years) and a SARS-CoV-2 infection confirmed by PCR in South Korea, Han et al. detected viral RNA in 20 asymptomatic children for a mean duration of 14.1 days compared with a mean duration of 19.1 days in 71 symptomatic children. ${ }^{26}$

Detection of viral RNA does not necessarily indicate the presence of infectious virus. However, L'Huillier et al. found infectious SARS-CoV-2 in children of all ages, and reported that higher RNA levels were associated with an increased probability of detection of infectious virus. ${ }^{27}$ It remains unknown whether symptomatic children have higher viral loads than asymptomatic children.

\section{Outbreak in an Overnight Youth Camp}

In a retrospective cohort study of an outbreak in 597 attendees of an overnight youth camp in the US state of Georgia between June 17 and 27, 2020, Szablewski et al. found younger children were indeed at least as likely as older attendees to be infected with SARS-CoV-2. In this study, 51 out of 100 children aged 6 to 10 years tested positive for SARS-CoV-2 (51\%), compared with 180 out of 409 children and adolescents aged 11 to 17 years (44\%), and 29 out of 88 adults aged 18 to 59 years $(33 \%) .{ }^{13}$ At the time, the incidence in Georgia was at 1,009 new daily cases per 10 million inhabitants, with an effective reproduction number of $1.18 .{ }^{28,29}$ The study suggests that young children can have attack rates similar to those of older children, 
adolescents and adults under conditions that are conducive to outbreaks, such as high local transmission and overnight stays in dormitories.

\section{Ecological Studies on School Closures}

In a nationwide interrupted time series of all 50 US states between March 9 and May 7, 2020, Auger et al. found that statewide school closures were associated with a $62 \%$ relative reduction in the incidence of COVID-19 cases (95\% confidence interval 49 to $71 \%$ ) and a $58 \%$ relative reduction in deaths from COVID-19 (95\% confidence interval 46 to $68 \%$ ). These associations were largest in states with low case numbers at the time of school closure. ${ }^{30}$

In a prospective cohort study of 144 countries, states or provinces between March 7 and March 27, 2020, Jüni et al. found a 37\% reduction in epidemic growth associated with school closures (95\% confidence interval 22 to $48 \%$ ). ${ }^{31}$ The other public health interventions studied were restrictions of mass gatherings and social distancing measures. In a multivariable analysis, there was a strong association of the reduction in epidemic growth with the number of implemented public health interventions ( $p$ for trend $=0.001$ ). ${ }^{31}$

In a subsequent retrospective study in 149 countries or regions between January 1 and May 30, 2020, Islam et al. found school closures, in combination with other types of public health interventions, to be associated with an average reduction in incidence of $13 \%$ (95\% confidence interval 11 to $15 \%)^{32}$

All three studies on school closures ${ }^{30-32}$ were observational, ecological studies. Causality can therefore not be established. In addition, it was not possible to disentangle the independent impact of school closures from the impact of other public health interventions in the studies. Finally, school closures are associated with important social and economic harms, ${ }^{8}$ which were not analysed in any of the studies.

\section{Case Studies on School Openings}

Table 1 presents the characteristics of countries and states used as case studies on school openings below, compared with the province of Ontario.

\begin{tabular}{|c|c|c|c|c|c|}
\hline & Netherlands & $\begin{array}{l}\text { Saxony, } \\
\text { Germany }\end{array}$ & Denmark & Israel & $\begin{array}{l}\text { Ontario, } \\
\text { Canada }\end{array}$ \\
\hline Population (million inhabitants) & 17.4 & 4.1 & 5.8 & 9.1 & 14.4 \\
\hline Area $\left(1,000 \mathrm{~s} \mathrm{~km}^{2}\right)$ & 41.5 & 18.4 & 42.9 & 22.1 & 1,076 \\
\hline Average density $\left(1,000\right.$ inhabitants $\left./ \mathrm{km}^{2}\right)$ & 0.42 & 0.22 & 0.14 & 0.41 & 0.01 \\
\hline Highest urban density $\left(1,000 \text { inhabitants } / \mathrm{km}^{2}\right)^{\mathrm{a}}$ & 2.7 & 2.5 & 2.0 & 6.3 & 2.8 \\
\hline GINI coefficient ${ }^{b}$ & 28.5 & $31.9^{c}$ & 28.7 & 41.3 & $33.8^{\mathrm{c}}$ \\
\hline Confidence in national government ${ }^{\mathrm{c}}(\%)$ & 57 & $42^{\mathrm{c}}$ & 53 & 34 & $52^{\mathrm{c}}$ \\
\hline
\end{tabular}

Table 1. Characteristics of countries and states used as case studies on school openings below, compared with the province of Ontario

${ }^{a}$ Highest urban density refers to the city with the highest urban density in the country, state or province. ${ }^{b}$ The GINI coefficient ${ }^{33}$ represents the income inequality or wealth inequality within a country or state; higher values indicate higher inequality. 'GINI coefficients and confidence in national government for Saxony, Germany and Ontario, Canada are at country level. 'The confidence in national government ${ }^{34}$ represents the percentage of 'yes' answers to the question "In this country, do you have confidence in each of the following, or not? How about national government?".

The Netherlands, Denmark and Saxony, Germany appear similar to Ontario in terms of their urban density and GINI coefficient, whereas Israel is characterized by a considerably higher urban density and socioeconomic inequalities, as indicated by the GINI coefficient. Confidence in the national government in the Netherlands and Denmark appear to be similar to Ontario, whereas confidence in Israel and Saxony appear to be lower. 


\section{Netherlands}

On May 11, 2020, the Netherlands opened primary schools and childcare facilities, ${ }^{35}$ when the incidence was 138 new daily cases per 10 million inhabitants, with a downward trend and an effective reproduction number of $0.76 .{ }^{28,29}$

Children attended schools only $50 \%$ of the time, with class sizes reduced to $50 \%{ }^{36,37}$ Strict hand hygiene was required. Children younger than 13 years did not have to maintain physical distancing or wear masks, but cohorting was recommended to limit contact between groups of children. Adults in schools were recommended to stay 1.5 metres apart from each other and from children. ${ }^{38}$

On May 11, the country also lifted other restrictions outside of schools: outdoor group sports could resume for all ages, as long as physical distancing of 1.5 metres could be maintained for individuals aged 13 years and above; professions requiring close contact with clients, such as hairdressers and driving instructors were permitted to return to work; and libraries were reopened. ${ }^{36,39}$ Physical distancing of 1.5 metres was required throughout, and contact tracing was done at the municipal level. ${ }^{38}$

On June 1 , cinemas, restaurants, bars, and cafes were permitted to open, with a maximum capacity of 30 people, provided that physical distancing of 1.5 metres could be maintained. From June 1 onwards, everyone aged 13 years or older travelling on public transport was also required to wear a face mask. ${ }^{36,39}$

Secondary schools reopened on June $2,^{40}$ when the incidence was 116 new daily cases per 10 million inhabitants, with an effective reproduction number of $1.65 .{ }^{28,29}$ Children 13 to 18 years of age were not required to physically distance from each other, but students in higher education and adults in schools were required to stay 1.5 metres apart from each other and from children. ${ }^{38}$ Students were also required to self-monitor for symptoms and were not permitted to go to school if they had symptoms, or if a household member was symptomatic. Additionally, students travelling from high-risk countries were required to quarantine for 10 days. ${ }^{41}$ No masks were required. ${ }^{38}$ On June 8 , primary schools returned to full schedules. ${ }^{38}$

On June 3, an outbreak was reported in a primary school, when two teachers tested positive for SARS-CoV-2 and 7 students reported gastrointestinal symptoms, leading to the closure of the school. ${ }^{42}$ However, there were only a few school outbreaks reported until the beginning of the summer holidays on July 4 , when the incidence was 38 new daily cases per 10 million inhabitants, with an effective reproduction number of $0.78 .^{28,29}$

\section{Saxony, Germany}

On May 18, 2020, schools and day care facilities opened in Saxony, Germany, ${ }^{43,44}$ when the incidence was 59 new daily cases per 10 million inhabitants, ${ }^{45}$ and Germany's effective reproduction number was $0.82 .{ }^{28,29}$

Entry to schools and day care facilities was only permitted after symptom screening, or a medical note providing an alternative explanation for symptoms resembling SARS-CoV-2. When dropping off or picking up students, adults were required to wear masks. Any teachers who showed symptoms of illness were required to get tested for COVID-19. Any contact with a known COVID-19 case needed to be reported to the school immediately. ${ }^{44}$ Required hygiene regulations for each school facility were posted at the entrance of each building, hands had to be washed immediately upon entry, disinfecting stations were added throughout the buildings and increased sanitization protocols, such as cleaning of used rooms, surfaces and objects twice daily, were in place. ${ }^{44}$ Strict cohorting was required with separation of 
classes, and a daily contact log was required for all schools to note the composition of classes and their contact with teachers and other school staff. ${ }^{44,46}$ Classrooms were required to be ventilated several times a day. ${ }^{44}$ Masks were recommended for adults, but not for children. ${ }^{46}$

Just before school opening, on May 15, church services, weddings and funerals were permitted in Saxony, provided that physical distancing of 1.5 metres could be maintained. Restaurants, hotels, and boarding houses reopened. Physical distancing of 1.5 metres was required throughout. ${ }^{47}$

From May 25 to June 30, a seroprevalence study was conducted in 1,538 students aged 14 to 16 and 507 teachers from 13 schools. ${ }^{43}$ The non-peer-reviewed study found that 11 students and one teacher, coming from 7 schools, were seropositive for SARS-CoV-2, resulting in a seroprevalence $0.7 \%$ among students and $0.2 \%$ among teachers. ${ }^{43}$

There were no school outbreaks reported until the beginning of the summer holidays on July 17, when the incidence in Saxony was 5 new daily cases per 10 million inhabitants. ${ }^{45}$

\section{Denmark}

On April 15, 2020, Denmark permitted the opening of primary schools and childcare facilities to optional attendance for students under the age of 12 years, provided that city councils considered opening justifiable. Education institutions for older youth and adults were permitted to reopen only for exam students, and with a reduced schedule. ${ }^{35,48,49}$ At the time, the incidence was 322 new daily cases per 10 million inhabitants, but with a consistent downward trend and an effective reproduction number of $0.89 .{ }^{28,29}$ By the second week of school opening, $80 \%$ to $90 \%$ of primary students, and $50 \%$ of preschool and kindergarten students had returned to school. ${ }^{49}$

Students were screened through temperature and symptom checks upon arrival, class sizes were reduced to allow for 2-metre physical distancing, ${ }^{35,49}$ with typically no more than 11 students per classroom. Assigned desks were spaced 2 metres apart $^{50}$ and use of outdoor spaces was recommended. Gyms and additional school classrooms were used to permit the recommended distancing between students. ${ }^{35,49,51}$ Student arrivals were staggered. No family members were permitted inside the schools. ${ }^{49,50}$ Frequent hand washing and cleaning protocols were implemented. Cohorting was required, with separation of classes. Physical distancing of 2 metres was mandated for students of all ages and adults. Students and staff were not required to wear masks. ${ }^{49}$

On April 20, restrictions on professions requiring close contact with clients were lifted. All other establishments such as churches, restaurants, malls and sports facilities remained closed. ${ }^{52}$ Outside of schools, physical distancing of 2 metres continued to be required for everyone. ${ }^{53}$

On May 11, the country opened the entire retail sector, including shopping malls, and reduced the physical distancing requirement to 1 metre. ${ }^{52,53}$ On May 18, restaurants and cafes began to open. ${ }^{52}$

On May 18 , students aged 12 to 16 years returned to school, ${ }^{48}$ when the incidence was 131 new daily cases for 10 million inhabitants, with an effective reproduction number of $0.77 .^{28,29}$ 
On May 27, students aged 17 to 19 returned to school, ${ }^{48}$ when the incidence was 93 new daily cases for 10 million inhabitants, with an effective reproduction number of $0.83 .^{28,29}$

On June 12, Northern Jutland reported 5 cases in three schools; 17 classes were quarantined accordingly. No additional cases were subsequently reported in these schools. ${ }^{54}$ No further school outbreaks were reported until the beginning of the summer holidays on June 26 , when the incidence was 45 new daily cases per 10 million inhabitants, with an effective reproduction number of $0.91 .{ }^{28,29}$

Table 2 presents a comparison of public health measures in Denmark and Israel during school openings.

\begin{tabular}{|c|c|c|}
\hline & Denmark & Israel \\
\hline \multicolumn{3}{|l|}{ Timeline } \\
\hline Date of $1^{\text {st }}$ school opening & April 15 & May 3 \\
\hline Date of $2^{\text {nd }}$ school opening & May 18 & May 17 \\
\hline Date of $3^{\text {rd }}$ school opening & May 27 & - \\
\hline 1st day of school closure & June 27 & May 27 \\
\hline Purpose of school closure & Holiday & Outbreak \\
\hline \multicolumn{3}{|l|}{ School-specific measures } \\
\hline Stepwise opening of schools by age & $\checkmark$ & $\checkmark$ \\
\hline Opening of higher education (age 18+) & $x$ & $\checkmark$ \\
\hline School attendance rate & $80-90 \%$ & $60 \%$ \\
\hline Reduced class sizes & $\checkmark$ & $x^{a}$ \\
\hline Shorter school days & $\checkmark$ & $x^{a}$ \\
\hline Cohorting & $\checkmark$ & $x$ \\
\hline Hand hygiene protocols & $\checkmark$ & $\checkmark$ \\
\hline Sanitization protocols & $\checkmark$ & $-\mathrm{b}$ \\
\hline Temperature and symptom checks & $\checkmark$ & $-b$ \\
\hline Staggered student arrivals & $\checkmark$ & $-b$ \\
\hline Visitor restrictions & $\checkmark$ & $-\mathrm{b}$ \\
\hline Well ventilated classrooms & $\checkmark$ & $x$ \\
\hline Mandatory masks & $x$ & $\sqrt{c}$ \\
\hline Outdoor schooling & $\checkmark$ & $x$ \\
\hline Physical distancing in classrooms & $\checkmark$ & $x$ \\
\hline School outbreaks and closures due to outbreaks & $x$ & $\checkmark$ \\
\hline \multicolumn{3}{|c|}{ Public health interventions within 1 month after $1^{\text {st }}$ school opening } \\
\hline Physical distancing & 1 metre & 2 metres \\
\hline Maximum public gathering size & 10 & 50 \\
\hline Contact tracing & $-\mathrm{b}$ & $\checkmark$ \\
\hline Contact-based professions not permitted & $x$ & $x$ \\
\hline Retail (shops, malls) closed & $x$ & $x$ \\
\hline Restaurants, cafes closed & $\checkmark$ & $x$ \\
\hline Pubs, clubs, and bars closed & $\checkmark$ & $x$ \\
\hline Places of worship closed & $\checkmark$ & $x$ \\
\hline Indoor sports not permitted & $\checkmark$ & $x$ \\
\hline Outdoor sports not permitted & $x$ & $x$ \\
\hline
\end{tabular}

Table 2. Summary of measures taken during school openings and concurrent public health interventions in Denmark and Israel

"In Israel, reduced class sizes with 15 students, and shortened school days were only in place from May 3 to May $17 .{ }^{50,55}{ }^{b}$ Not reported. ${ }^{c}$ Children above the age of 7 years and adults were required to wear masks in school; however, throughout the duration of a heatwave from May 19 to 21, this requirement was lifted before the school outbreak reported by Stein-Zamir et al. ${ }^{56}$

\section{Israel}

On May 3, 2020, Israel opened kindergarten, grades 1 to 3 , and grades 11 to $12,{ }^{56}$ when the incidence was 100 new daily cases per 10 million inhabitants, with an effective reproduction number of $0.60 .{ }^{28,29}$ Reported requirements included class sizes of 15 students, shortened 5-hour school days, the utilization of empty classrooms and mandatory mask wearing for students above the age of $7 .{ }^{50,55}$ 
Reportedly, only $60 \%$ of eligible students attended school at the time of initial opening. ${ }^{55}$

On May 7, specific gatherings of up to 20 people were permitted, including openspace weddings and funerals, and certain indoor ceremonies. ${ }^{57}$ Contact tracing was implemented. ${ }^{56}$

On May 17, all remaining schools opened, ${ }^{56}$ when the incidence had decreased to 25 new daily cases per 10 million inhabitants, with an effective reproduction number of $0.64{ }^{28,29}$ A strict hand washing protocol and a physical distancing requirement of 2 metres during meals were specified on this date. ${ }^{58}$ Limitations on class sizes were lifted. ${ }^{50}$ Mask wearing continued to be required. ${ }^{58}$

On May 20, the permitted size of gatherings was increased to 50 people in places of worship; physical distancing of 2 metres was required. ${ }^{59}$

On May 27, the country opened restaurants, bars and pubs with a maximum capacity of 100 people; as well as swimming pools, and tourist attractions, physical distancing of 2 metres continued to be required. ${ }^{60}$

On May 27, the first school outbreak was reported. ${ }^{56}$ A heatwave from May 19 to May 21, resulted in the exemption of students from wearing masks. Stein-Zamir et al. report that air-conditioning systems for each classroom continuously recirculated air at this school. ${ }^{56}$ Class sizes in the school were between 35 to 38 students, not allowing for physical distancing, and students attended school for up to 40 hours a week..$^{56} 153$ out of 1,161 tested students (13\%) and 25 out of 151 tested staff (17\%) tested positive for SARS-CoV-2. ${ }^{56}$

By June 8, 139 educational institutions across the country had closed due to outbreaks, ${ }^{50}$ when the incidence was 179 new daily cases per 10 million inhabitants, with an effective reproduction number of $1.31 .{ }^{28,29}$

On June 14, establishments such as theatres and event halls were permitted to open at $75 \%$ capacity with no maximum occupancy; permission had to be granted for gatherings of over 500 people. ${ }^{61}$ Physical distancing, mask wearing and hygiene maintenance were required. ${ }^{61}$

At the beginning of the summer holidays for primary schools on July 1 , the incidence was 946 new daily cases per 10 million inhabitants, with an effective reproduction number of $1.46 .^{28,29}$

Table 2 presents a comparison of public health measures in Israel and Denmark during school openings, with considerably less school-specific measures and public health interventions in place in Israel. The higher urban density, higher socioeconomic inequalities, and lower confidence in national government reported in Table 1 for Israel, as compared to Denmark, may have contributed to the observed differences in outcome. As of August 25, the majority of outbreaks occurred in communities of low socio-economic status or ethnic minorities. ${ }^{62}$

\section{Interpretation}

Early suggestions that children are considerably less important drivers of SARS-CoV2 transmission than adults are not confirmed by recent research.

There may be biological and behavioural factors that could influence susceptibility in different age groups. Lower levels of ACE2, the receptor used by the virus to infect cells, in the nasal mucosa, could result in a potentially lower susceptibility of younger children to SARS-CoV-2 infection. This lower biological susceptibility could be offset by a higher number of social contacts in some children, and by different 
reactions to public health interventions than adults.

Children could play a relevant role in SARS-CoV-2 transmission and school closures may have been important contributors to the containment of the COVID-19 pandemic.

Case studies of school openings in some European countries suggest that school openings can be safe provided that local transmission is low and appropriate measures are in place to prevent or contain potential outbreaks. School openings without adequate control measures and/or public health interventions lifted too early could be associated with a high number of school outbreaks, as suggested by the case study in Israel.

Gaps in knowledge include information on school-specific testing, quarantine, and contact tracing strategies in the countries discussed in the case studies; the epidemiology of SARS-CoV-2 infections in the presence of seasonal influenza outbreaks and other respiratory viral infections; the epidemiology of SARS-CoV-2 infections during the colder winter months, when people will spend most of their time indoors; the relative importance of different measures used to prevent or contain outbreaks in schools; and the relative importance of different settings (home, schools, community) for the role of children in SARS-CoV-2 transmission.

Public health interventions appear to be as important and impactful to control SARSCoV-2 transmission in children as in adults. The interventions will need to be tailored to the age-specific social and developmental requirements of children, while also taking into account their potential challenges and harms.

It appears important to include children as part of any surveillance, testing and control strategy, while bearing in mind that children are more likely than adults to remain asymptomatic after SARS-CoV-2 infection.

\section{Methods Used for This Science Brief}

We searched PubMed, Google Scholar, the COVID-19 Rapid Evidence Reviews, the Joanna Briggs Institute's COVID-19 Special Collection, LitCovid in PubMed, the Oxford COVID-19 Evidence Service, the World Health Organization's Global Literature on Coronavirus Disease, and other COVID-19 specific resources listed by the Guidelines International Network and the McMaster Health Forum. In addition, we retrieved reports citing relevant articles through Google Scholar and reviewed references from identified articles for additional studies. The search was last updated on August 27, 2020.

\section{Author Contributions}

PJ, AM and PB wrote the first draft of the science brief. All authors contributed to the conception of the science brief, revised it critically for important intellectual content, and approved the final version.

\section{References}

1. Cauchemez S, Valleron A-J, Boëlle P-Y, Flahault A, Ferguson NM. Estimating the impact of school closure on influenza transmission from Sentinel data. Nature. 2008;452(7188):750-754. https://doi.org/10.1038/nature06732

2. Wu JT, Cowling BJ, Lau EHY, et al. School closure and mitigation of pandemic (H1N1) 2009, Hong Kong. Emerg Infect Dis. 2010;16(3):538-541. https:// doi.org/10.3201/eid1603.091216 
3. Livingston E, Bucher K. Coronavirus Disease 2019 (COVID-19) in Italy. JAMA. Published online March 17, 2020. https://doi.org/10.1001/jama.2020.4344

4. Lu X, Zhang L, Du H, et al. SARS-CoV-2 Infection in Children. $\mathrm{N}$ Engl J Med. 2020;382(17):1663-1665. https://doi.org/10.1056/NEJMc2005073

5. Qiu H, Wu J, Hong L, Luo Y, Song Q, Chen D. Clinical and epidemiological features of 36 children with coronavirus disease 2019 (COVID-19) in Zhejiang, China: an observational cohort study. Lancet Infect Dis. 2020;20(6):689-696. https:// doi.org/10.1016/S1473-3099(20)30198-5

6. Zimmermann P, Curtis N. Coronavirus Infections in Children Including COVID-19: An Overview of the Epidemiology, Clinical Features, Diagnosis, Treatment and Prevention Options in Children. Pediatr Infect Dis J. 2020;39(5):355-368. https:// doi.org/10.1097/INF.0000000000002660

7. Public Health Ontario. COVID-19 Infection in Children: January 15, 2020 to July 13, 2020. Public Health Ontario; 2020:11. https://www.publichealthontario.ca/-/ media/documents/ncov/epi/2020/05/covid-19-epi-infection-children.pdf?la=en

8. Viner RM, Russell SJ, Croker $\mathrm{H}$, et al. School closure and management practices during coronavirus outbreaks including COVID-19: a rapid systematic review. Lancet Child Adolesc Health. 2020;0(0). https://doi.org/10.1016/S2352-4642(20) 30095-X

9. National Centre for Immunisation Research and Surveillance. COVID-19 in Schools - the Experience in NSW.; 2020. Accessed July 23, 2020. http:// ncirs.org.au/covid-19-in-schools

10. Macartney K, Quinn H, Pillsbury A, et al. Transmission of SARS-CoV-2 in Australian educational settings: a prospective cohort study. Lancet Child Adolesc Health. Published online August 3, 2020. https://doi.org/10.1016/S2352-4642 (20)30251-0

11. Lee B, Raszka WV. COVID-19 transmission and children: the child is not to blame. Pediatrics. 2020;146(2). https://doi.org/10.1542/peds.2020-004879

12. Heald-Sargent T, Muller WJ, Zheng X, Rippe J, Patel AB, Kociolek LK. Age-related differences in nasopharyngeal severe acute respiratory syndrome coronavirus 2 (SARA-CoV-2) levels in patients with mild to moderate coronavirus disease 2019 (COVID-19). JAMA Pediatr. Published online July 30, 2020. https:// doi.org/10.1001/jamapediatrics.2020.3651

13. Szablewski CM. SARS-CoV-2 transmission and infection among attendees of an overnight camp - Georgia, June 2020. MMWR Morb Mortal Wkly Rep. 2020;69. https://doi.org/10.15585/mmwr.mm6931e1

14. Zhang J, Litvinova $M$, Liang $Y$, et al. Changes in contact patterns shape the dynamics of the COVID-19 outbreak in China. Science. Published online April 29, 2020. https://doi.org/10.1126/science.abb8001

15. Park YJ, Choe YJ, Park O, et al. Contact Tracing during Coronavirus Disease Outbreak, South Korea, 2020. Emerging Infect Dis. 2020;26(10). https:// doi.org/10.3201/eid2610.201315

16. Sethuraman N, Jeremiah SS, Ryo A. Interpreting diagnostic tests for SARS-CoV-2. JAMA. Published online May 6, 2020. https://doi.org/10.1001/jama.2020.8259

17. Government of Ontario. Extracts from the integrated Public Health Information System (iPHIS) - Ontario Data Catalogue. Ontario.ca. Published 2020. Accessed August 27, 2020. https://data.ontario.ca/dataset/extracts-from-the-integrated- 
public-health-information-system-iphis

18. Stringhini S, Wisniak A, Piumatti G, et al. Seroprevalence of anti-SARS-CoV-2 IgG antibodies in Geneva, Switzerland (SEROCoV-POP): a population-based study. The Lancet. 2020;0(0). https://doi.org/10.1016/S0140-6736(20)31304-0

19. Pollán M, Pérez-Gómez B, Pastor-Barriuso R, et al. Prevalence of SARS-CoV-2 in Spain (ENE-COVID): a nationwide, population-based seroepidemiological study. Lancet. 2020;0(0). https://doi.org/10.1016/S0140-6736(20)31483-5

20. Bunyavanich S, Do A, Vicencio A. Nasal gene expression of angiotensinconverting enzyme 2 in children and adults. JAMA. 2020;323(23):2427-2429. https://doi.org/10.1001/jama.2020.8707

21. Yonker LM, Neilan AM, Bartsch $Y$, et al. Pediatric SARS-CoV-2: Clinical Presentation, Infectivity, and Immune Responses. J Pediatr. 2020;0(0). https:// doi.org/10.1016/j.jpeds.2020.08.037

22. Davies NG, Klepac P, Liu Y, Prem K, Jit M, Eggo RM. Age-dependent effects in the transmission and control of COVID-19 epidemics. Nat Med. Published online June 16, 2020. https://doi.org/10.1038/s41591-020-0962-9

23. Mossong J, Hens $\mathrm{N}$, Jit $\mathrm{M}$, et al. Social contacts and mixing patterns relevant to the spread of infectious diseases. PLoS Med. 2008;5(3):e74. https:// doi.org/10.1371/journal.pmed.0050074

24. Government of Canada. COVID-19: Risk mitigation tool for child and youth settings operating during the pandemic. Canada.ca. Published July 20, 2020. Accessed August 26, 2020. https://www.canada.ca/en/public-health/services/ diseases/2019-novel-coronavirus-infection/guidance-documents/covid-19-riskmitigation-tool-child-youth-settings-operating-during-pandemic.html

25. Jones TC, Mühlemann B, Veith T, et al. An analysis of SARS-CoV-2 viral load by patient age. medRxiv. Published online June 9, 2020:2020.06.08.20125484. https://doi.org/10.1101/2020.06.08.20125484

26. Han MS, Choi EH, Chang SH, et al. Clinical Characteristics and Viral RNA Detection in Children With Coronavirus Disease 2019 in the Republic of Korea. JAMA Pediatr. Published online August 28, 2020. https://doi.org/10.1001/ jamapediatrics.2020.3988

27. L'Huillier AG, Torriani G, Pigny F, Kaiser L, Eckerle I. Culture-competent SARSCoV-2 in nasopharynx of symptomatic neonates, children, and adolescents. Emerging Infect Dis. 2020;26(10). https://wwwnc.cdc.gov/eid/article/26/10/202403_article

28. Johns Hopkins University (JHU). COVID-19 dashboard by the center for systems science and engineering at Johns Hopkins University. Johns Hopkins Coronavirus Resource Center. Published August 20, 2020. Accessed August 20, 2020. https:// coronavirus.jhu.edu/map.html

29. Institute of Global Health, Faculty of Medicine, University of Geneva, Swiss Data Science Center, ETH Zürich-EPFL. COVID-19 daily epidemic forecasting dashboard. COVID-19 Epidemic Forecasting. Published August 20, 2020. Accessed August 20, 2020. https://renkulab.shinyapps.io/COVID-19-EpidemicForecasting/

30. Auger KA, Shah SS, Richardson T, et al. Association between statewide school closure and COVID-19 incidence and mortality in the US. JAMA. Published online July 29, 2020. https://doi.org/10.1001/jama.2020.14348 
31. Jüni $P$, Rothenbühler $M$, Bobos $P$, et al. Impact of climate and public health interventions on the COVID-19 pandemic: a prospective cohort study. CMAJ. 2020;192(21):E566-E573. https://doi.org/10.1503/cmaj.200920

32. Islam N, Sharp SJ, Chowell G, et al. Physical distancing interventions and incidence of coronavirus disease 2019: natural experiment in 149 countries. BMJ. 2020;370. https://doi.org/10.1136/bmj.m2743

33. World Bank. GINI index (World Bank estimate) | Data. World Bank Data. Accessed August 24, 2020. https://data.worldbank.org/indicator/SI.POV.GINI

34. Organisation for Economic Co-operation and Development. Trust in Government, Policy Effectiveness and the Governance Agenda. OECD; 2013. Accessed August 27, 2020. https://doi.org/10.1787/gov_glance-2013-en

35. European Centre for Disease Prevention and Control. COVID-19 in Children and the Role of School Settings in COVID-19 Transmission. ECDC; 2020. Accessed August 6, 2020. https://www.ecdc.europa.eu/sites/default/files/documents/ COVID-19-schools-transmission-August\%202020.pdf

36. European Commission Joint Research Centre. ECML COVID-19 dashboard. Published August 20, 2020. Accessed August 20, 2020. https://covidstatistics.jrc.ec.europa.eu/Measure/DashboardMeasures?view=1

37. Euronews. Dutch primary schools to reopen in easing of COVID-19 restrictions. euronews. https://www.euronews.com/2020/04/21/dutch-primary-schools-toreopen-part-time-on-may-11-in-easing-of-covid-19-restrictions. Published April 21, 2020. Accessed August 20, 2020.

38. National Institute for Public Health. Children and COVID-19. Rijksinstituut voor Volksgezondheid en Milieu. Published August 19, 2020. Accessed August 20, 2020. https://www.rivm.nl/en/novel-coronavirus-covid-19/children-and-covid19

39. Zaken $M$ van A. Avoid busy places and stay 1.5 metres away from others. Government Webpage. Published May 6, 2020. Accessed August 20, 2020. https://www.government.nl/latest/news/2020/05/06/avoid-busy-places-andstay-1.5-metres-away-from-others

40. Deutsch A. Dutch schools, cafes and museums to reopen in June. Reuters. https://www.reuters.com/article/us-health-coronavirus-netherlands-measuridUSKBN22V2RI. Published May 19, 2020. Accessed August 20, 2020.

41. Ministry of Social Affairs and Employment. Veelgestelde vragen van ouders over coronavirus en kinderopvang - Coronavirus COVID-19 - Rijksoverheid.nl. Government of Netherlands. Published March 20, 2020. Accessed August 24, 2020. https://www.rijksoverheid.nl/onderwerpen/coronavirus-covid-19/oudersscholieren-en-studenten-kinderopvang-en-onderwijs/ouders

42. Deutsch A. Dutch school shuts after teachers test positive for COVID-19. Reuters. https://www.reuters.com/article/us-health-coronavirus-netherlandsschool-idUSKBN23A2A8. Published June 3, 2020. Accessed August 23, 2020.

43. Armann JP, Unrath M, Kirsten C, Lueck C, Dalpke A, Berner R. Anti-SARS-CoV-2 IgG antibodies in adolescent students and their teachers in Saxony, Germany (SchoolCoviDD19): very low seropraevalence and transmission rates. medRxiv. Published online July 17, 2020. https://doi.org/10.1101/2020.07.16.20155143

44. Saxon State Ministry for Social Affairs and Social Cohesion. General ruling to regulate the operation of day care facilities and schools in connection with the fight against the SARS-CoV-2 pandemic. Published online May 12, 2020. 
Accessed August 21, 2020. https://www.coronavirus.sachsen.de/ download/2020-05-14_Allgemeinverfuegung_Schule_EN.pdf

45. Robert Koch-Institut: COVID-19 dashboard. Robert Koch-Institut: COVID-19Dashboard. Published August 20, 2020. Accessed August 20, 2020. https:// experience.arcgis.com/experience/478220a4c454480e823b17327b2bf1d4/ page/page_0/

46. Saxon State Ministry for Culture. Children are allowed to go to daycare centers and elementary schools again. sachsen.de. Published May 8, 2020. Accessed August 21, 2020. https://medienservice.sachsen.de/medien/news/236718

47. Saxon State Ministry for Social Affairs and Social Cohesion. Further relaxation of corona restrictions decided - restaurants, hotels, theaters and cinemas are allowed to reopen. sachsen.de. Published May 12, 2020. Accessed August 21, 2020. https://medienservice.sachsen.de/medien/news/236832

48. Stage HB, Shingleton J, Ghosh S, Scarabel F, Pellis L, Finnie T. Shut and re-open: the role of schools in the spread of COVID-19 in Europe. medRxiv. Published online June 26, 2020:2020.06.24.20139634. https://doi.org/10.1101/2020. 06.24 .20139634

49. Melnick H, Darling-Hammond L. Reopening Schools in the Context of COVID-19: Health and Safety Guidelines from Other Countries. Learning Policy Institute; 2020:13. https://files.eric.ed.gov/fulltext/ED606555.pdf

50. Guthrie BL, Tordoff DM, Bvm JM, et al. Summary of School Re-Opening Models and Implementation Approaches during the COVID-19 Pandemic. Washington State Department of Health; Metacenter of Pandemic Preparedness; Start Center; 2020:18. https://globalhealth.washington.edu/sites/default/files/COVID -19\%20Schools\%20Summary\%20\%28updated\%29.pdf

51. Sheikh A, Sheikh A, Sheikh Z, Dhami S. Reopening schools after the COVID-19 lockdown. J Glob Health. 2020;10(1). https://doi.org/10.7189/jogh.10.010376

52. Danish Police. Controlled reopening of Denmark. Published May 7, 2020. Accessed August 20, 2020. https://politi.dk/en/coronavirus-in-denmark/ controlled-reopening-of-denmark

53. Danish Health Authority. Vi skal alle fortsat holde afstand og vise hensyn - men hvis vi holder høj hygiejne, så kan vi rykke en smule tættere sammen. Published May 10, 2020. Accessed August 21, 2020. https://www.sst.dk/da/ nyheder/2020/vi-skal-alle-fortsat-holde-afstand-og-vise-hensyn-saa-kan-vi-rykke -en-smule-taettere-sammen

54. Bronnum MG. Ikke flere smittede på Hjørring-skoler: - Det går rigtig fint. TV2 Nord. https://www.tv2nord.dk/hjoerring/ikke-flere-smittede-paa-hjoerringskoler-det-gaar-rigtig-fint. Published June 24, 2020. Accessed August 24, 2020.

55. Sokol S. Israeli schools are reopening, but fears and confusion keep many kids at home | The Times of Israel. The Times of Israel. https://www.timesofisrael.com/ israeli-schools-reopen-but-fears-and-confusion-keep-many-kids-at-home/. Published May 14, 2020. Accessed August 20, 2020.

56. Stein-Zamir C, Abramson N, Shoob H, et al. A large COVID-19 outbreak in a high school 10 days after schools' reopening, Israel, May 2020. Eurosurveillance. 2020;25(29). https://doi.org/10.2807/1560-7917.ES.2020.25.29.2001352

57. Government of Israel. The national effort to combat the coronavirus - police guidelines \& information. GOV.IL. https://www.gov.il/en/departments/news/ police_covid-19_eng_22032020. Published May 7, 2020. Accessed August 20, 2020. 
58. Prime Minister's Office. PM Netanyahu approves outline on opening the education system. GOV.IL. Published May 14, 2020. Accessed August 21, 2020. https://www.gov.il/en/departments/news/spoke_edu140520

59. Government of Israel. Reopening places of worship. GOV.IL. https://www.gov.il/ en/departments/news/19052020_05. Published May 19, 2020. Accessed August 20, 2020.

60. Ministry of Health, Government of Israel. Relief measures for the reopening of restaurants, bars, swimming pools, tourist attractions, and more.... GOV.IL. Published May 26, 2020. Accessed August 20, 2020. https://www.gov.il/en/ departments/news/26052020_01

61. Government of Israel. Bringing cultural activities back to life. GOV.IL. https:// www.gov.il/en/departments/news/24052020_02. Published May 24, 2020. Accessed August 20, 2020.

62. State of Israel, Ministry of Health. The Novel Coronavirus. Published 2020. Accessed August 25, 2020. https://govextra.gov.il/ministry-of-health/corona/ corona-virus/disclaimer/ 